\title{
On the Pragmatic Study of Euphemism and Its Application for English Teaching
}

\author{
Wu Shuang \\ School of Foreign Languages \\ East China Jiaotong University \\ Jiangxi Province, China \\ E-mail: 253309822@qq.com
}

\author{
Wang Ning \\ School of Foreign Languages \\ East China Jiaotong University \\ Jiangxi Province, China \\ E-mail: superning2008@163.com
}

\begin{abstract}
Euphemism, as a common linguistic phenomenon, is a mild or vague or periphrastic expression as a substitute for blunt precision or disagreeable truth. Based on the academic research done before, this thesis attempts to explore English euphemism from the pragmatic perspective as well as its application for non-English-major English teaching. Via the theoretical and empirical study, some specific strategies are also introduced in this thesis.
\end{abstract}

Keywords- Euphemism, Pragmatic Analysis, application, English Teaching

\section{INTRODUCTION}

Euphemism is a word deriving from the Greek, which literally means "to speak with manner or in a pleasant way" (Liu Chunbao, 2001). According to H.W.Fowler, "Euphemism is a mild or vague or periphrastic expression as a substitute for blunt precision or disagreeable truth."(1995) It is a mild, indirect and roundabout way to express oneself instead of using those vulgar, direct or embarrassing expressions. Meanwhile, euphemism is closely related to the psychological factor, which intends to achieve a successful and effective communication by giving the due respect and politeness to people and giving them delightful and comfortable feelings.

College teachers' work is done mainly through the verbal form which should be a good combination of both science and personal charm. The use of English euphemism is not only a full reflection of a person's artistic culture but also an agreeable and tactful strategy for the improvement of teaching effect. For the long run, the proper use of euphemism in class helps to establish a harmonious conversational atmosphere and conduct the trans-cultural communication in a better way.

However, an overall view of the current English course teaching sees more about the training of language skills, grammatical or structural analysis etc. The problem is becoming increasingly protruding particularly with the growing ignorance of the lecturing of cultural disparities and language strategies. Therefore, an introduction to euphemism and a pragmatic analysis on it is of great necessity and value for instructor-learner communication. The systematic study on it application and strategies of introduction to students ensures us a smooth and pleasant interaction.

\section{TYPE STYLE AND FONTS}

Regarding the important role euphemism plays in the college English teachers' discourse, a systematic and theoretical analysis of it is of great necessity and value. This part attempts to make the pragmatic analysis of euphemism under the guidance of those basic theories and principles. Meanwhile, typical examples in the daily teaching practice will be provided to illustrate the point.

\section{A. The Face-saving Theory}

Face is a matter of the emotional feeling in communication, which helps to establish a positive image and reflects the values and beliefs of the participants. Therefore, in order to win the respect from other people, euphemism is often used to save the participants' face. Otherwise, one's emotional feeling might be hurt at the cost of "lose of face".

According to the Face-saving Theory (FST) proposed by Brown and Levinson (1987), maintaining and keeping face is very important in people's communication. It involves both positive face and negative face. Positive face tends to win others' favor while negative face keeps one from being interfered. In social interaction, euphemism, as a replacement or harsh and blunt words, is an ideal way to prevent the degradation of interpersonal relationship and achieve the purpose of better communication.

The same theory could also be applied in class. Modern college students are mostly adults, who have broad horizon, creative mind and stronger eagerness to be recognized. They are more sensitive and self-respected. Therefore, their face particularly needs to be taken into consideration in class communication. No student expects to be corrected or criticized by an unkind teacher with harsh words. All teachers' insult, complaints, humiliation, tease or refute are threatening students' positive face. When teachers intend to reach an instructive aim and keep the students' face at the same time, the adoption of euphemism is a good way to achieve both.

Take an occasion in the college English class of nonEnglish major as an example. When the teacher asks the students to clean the blackboard, he should use the mild tone instead of the imperative one: "Would you mind cleaning the blackboard for me ?" This way not only shows the teacher's respect for the student but also helps to enhance the student's self-esteem and make them highly motivated. 
Here is another example to show how euphemism works in communication to save the students' face. When one student has the bad odor, the teacher says "you need guidance in developing good habits of hygiene." The teacher in the above example uses a more mild and euphemistic way to achieve a good balance between the purpose of education and the maintaining of the student's self-respect. The avoidance of using "dirty or smelly" or something like that keeps the student's face and indirectly reminds the student of his bad habit and encourages him to correct it in an active way.

Moreover, college students are psychologically immature without many life experiences. They are still lacking in the ability to tell the truth through the phenomenon which sometimes might mislead them. Therefore, some mistakes are unavoidable. Under this circumstance, what students really care is not what the teacher says, but the way how he says. This condition requires teachers to solve the problem by a more skillful speech tactic.

For example, when the student uses his strength to bully the weak, the teacher says "you need help in learning to use your leadership qualities democratically." When the student always keeps telling lies, the teacher says "You have difficulty in distinguishing between imaginary and factual information." It can be seen that euphemism is such a skillful and mild tactic to give students comment or suggestion. In this way, both face be kept and a good teaching effect be attained.

All in all, euphemism plays a positive role in English teaching practice. It keeps the faces of both teachers and students and creates a harmonious class atmosphere. With both self-esteem maintained, the English class for nonEnglish major could be effective and efficient.

\section{B. The Politeness Principle}

Politeness means to be kind and respectful to others. It is the symbol of human civilization as well as an important measurement of social activities. In real life, the improper use of languages might result in people's misunderstandings even conflicts. For example, instead of saying: "You have to finish your homework all by yourself! Don't use the reference book!", the teacher could say: "How I wish you did your homework all by yourself! I think you can." It is obvious the latter remark is more polite and euphemistic, which gives due respect to students and can be more easily accepted by them. Therefore, politeness avoids offense and is an important principle among people's communication.

According to Leech, the main purpose of the politeness principle can be summarized as to minimize the benefit to self and maximize the benefit to others. There are six maxims in the politeness principles: the tact maxim, the generosity maxim, the approbation maxim, the modesty maxim, the agreement maxim and the sympathy maxim.(1983)

Among the six maxims, the tact maxim is the fundamental one which is used for requirement or asking others to do something. It means to maximize benefit to others while minimize cost to others. When a teacher assigns something to the students, he must think from the students' perspective and employ some euphemistic expressions to make the students feel comfortable. In this way, students can be more cooperative, thus achieving the teaching aims smoothly.

Take the following table of teacher's different ways of speaking as an example:

\begin{tabular}{|l|l|}
\hline The direct way of speaking & $\begin{array}{l}\text { The euphemistic way of } \\
\text { speaking }\end{array}$ \\
\hline Repeat it! & $\begin{array}{l}\text { Excuse me, will you please } \\
\text { say it again? }\end{array}$ \\
\hline $\begin{array}{l}\text { You may raise your questions } \\
\text { now. }\end{array}$ & $\begin{array}{l}\text { If you have any questions, I'll } \\
\text { be glad to answer them. }\end{array}$ \\
\hline Read the whole passage. & $\begin{array}{l}\text { Would you like to read the } \\
\text { whole passage for me? }\end{array}$ \\
\hline Your duty report is awful. & $\begin{array}{l}\text { Your duty report still has } \\
\text { much space for improvement. }\end{array}$ \\
\hline $\begin{array}{l}\text { Tell me the answer to the } \\
\text { question! }\end{array}$ & $\begin{array}{l}\text { Would you please answer the } \\
\text { question? }\end{array}$ \\
\hline
\end{tabular}

From the table above, it can be seen that the euphemistic way of speaking is milder and can be more easily accepted by students. The use of more questioning sentences instead of imperatives makes students more comfortable and helps to create a good teaching environment and obtain better teaching effect.

Meanwhile, there are still other maxims of the politeness principle that teachers should observe in English teaching practice: the generosity maxims when the teacher promises to do something or response to the students' questions, the approbation maxim to avoid saying unpleasant things about others,etc.

Non-English major students have different knowledge background, major background, family background. They are independent individuals and have the strong demand to maintain their self-esteem. That requires the teacher to observe the politeness principle and learn to employ euphemism to give the students positive guidance and establish harmonious relationship between teachers and students.

\section{EUPHEMISM FOR ENGLISH TEACHING}

\section{A. The Accessibility of Introducing Euphemisms into College English Teaching}

Modernization confronts modern students with more opportunities to learn about foreign cultures and foreign values, which at the same time, become the barrier for mutual understanding and exchanges. Therefore, there is the coexistence of great challenges to acquire strong language competence and communicative competence, with which a successful communication could be well realized. English euphemism, as the important but difficult part in cross-cultural communication, is in great need of being introduced to college students.

The introduction to euphemism into English teaching helps to meet the students' psychological want. An improper dealing with mistakes might result in serious psychological damage to them. Euphemistic expressions help to keep students' face and maintain their self-respect, 
making them better realize their deficiencies and correct them.

The introduction to euphemism into English teaching helps to enhance the students' cross-culture awareness. Language and culture are closely related with the former one working as the carrier of the latter. The ignoring of cultural background or value-orientation might result in communicative failures. Therefore, students should not take language as a single subject to learn, but should combine it with a correct recognition of the relevant culture, thus enhancing communicative competence and cross-cultural awareness.

In a word, English euphemism not only helps to enhance the students' language competence, but also serves as a powerful device to achieve effective communication. It is accessible to introduce euphemisms into English teaching.

\section{B. Strategies of Introducing Euphemism to Students}

Since applying euphemism in English teaching is of great significance, it is necessary for English teachers to introduce euphemistic expressions to students and encourage them to output what they have learned in communication, thus improving students' language proficiency and communicative competence.

\section{Comparison}

The first strategy is Comparison which intends to make the students appreciate the power of euphemism by comparing the different effects between straightforward expressions and euphemistic expressions. Take the following table as an example:

\begin{tabular}{|l|l|}
\hline $\begin{array}{l}\text { Straightforward } \\
\text { expressions }\end{array}$ & Euphemistic expressions \\
\hline theft & borrow/remove/liberate \\
\hline divorce & great divide/break up \\
\hline blindness & $\begin{array}{l}\text { visually retarded/sight- } \\
\text { deprived }\end{array}$ \\
\hline the poor & $\begin{array}{l}\text { the deprived/the have- } \\
\text { nots }\end{array}$ \\
\hline
\end{tabular}

The above table clearly shows that euphemistic expressions help to soften or eliminate the offensive and blunt expressions and make the participants feel more comfortable. On the other hand, the comparison made above helps students understand under what circumstances English euphemism is employed and furthermore, gain a better understanding of the culture of English speaking countries.

Also the comparison inspires students with another comparison between the application of euphemism for the target language and that for their native one. Actually English euphemism and Chinese euphemism find many similarities in practical use. In both cultures, people deliberately adopt some mild and roundabout expressions towards some unmentionable topics like sex, disease, death, physical deficiency etc. Therefore, comparison helps the students not only master euphemism but also understand the relevant cultural factors, thus enhancing the ability of cross-cultural communication.

\section{TEACHING IN AN EUPHEMISTIC WAY}

Teachers' words and behaviors often have great influence on their students. Therefore, teaching is not just a process of transmitting knowledge, but also a real face-toface communication. When arising questions or correcting errors, straightforward expressions will offend students and make an embarrassing class atmosphere. In order to achieve a successful and effective communication, teachers should choose softer words and give the students positive guidance by employing euphemistic expressions in class, and furthermore, try to make the students gradually absorb them. For example, the teacher might employ understatement when a student failed in many tests by saying "I am sorry to find that you are an underachieve or a few main courses." The following shows some commonly used euphemistic expressions when the teacher is not satisfied with the students' performance in some aspects:

\section{1) Lazy Students}

He is sure to go far if he can use his resources fully. He'll get somewhere if he is highly motivated. He is an underachiever.

2) Students with low intelligence

He seems to be mentally retarded.

He is an exceptional/special child.

He is a bit slow for his age.

3) Students who keep telling lies

He has difficulty distinguishing between imaginary and factual information.

He is likely to embroider the truth a bit.

He has credibility gap.

4) Students who cheat at exams

He needs help in learning to adhere to rules and standards of fair play.

He depends on others to do his work.

It is inevitable that the teachers may have the students with different kinds of problems. The proper use of euphemism on one hand reveals the truth, on the other hand take the students' psychological demand into consideration. Sometimes teachers' non-verbal form of communication is also a kind of euphemistic expression such as putting one 's forefinger in front of the mouth, shaking one's head, wrinkling eye brows and so on. Only when a teacher learns to teach in an euphemistic way can the communicative goal and teaching effect be well achieved.

Besides proper euphemism, still sometimes, the teacher might use special sentence pattern or special tone to achieve the euphemistic purpose. For example, when a play is expected, the use of "could you please act out your dialogue?" could better motivate the student instead of "Act out your dialogue!" or when the teacher intends to ask the students "why didn't you finish your homework", the adoption of the rising tone shows a teacher's care and concern whereas the falling tone conveys the meaning of blame and disgust. 


\section{TEACHING AIDS}

Modern multimedia teaching aids provide an open way for introducing euphemism to students. English movies offer them a chance to appreciate euphemism in daily conversation; Political speeches provide more about euphemism in politics. Economic news broadcast gives more euphemistic terms in economy; still there are rich reading materials and other channels which help the students to pay attention to euphemism, better understand its application and learn from the native people when to use it and how to use it.

Besides, interesting activities out of class can also be organized, such as English corner, English lectures, English Salon etc. The full engagement in those activities also can broaden the students' horizon, strengthen their cultural understanding and help them to put the newly acquired euphemism into oral practice.

\section{CONCLUSION}

English Euphemism, as a commonly seen linguistic phenomenon, aims at using pleasant, mild or indirect words or phrases in place of the offensive, harsh and blunt ones. As a tactful language strategy, it is created for better interactive effect which can also be applied in college English class so as to attain the due teaching effect.

This thesis attempts to make the pragmatic analysis of English euphemism in the light of the Face Theory and the Politeness Principle. Illustrated by the typical examples collected from the teaching for non-English major students, it can be seen that euphemism is an agreeable and tactful strategy for teachers to save students' face, and achieve better communicative purpose and teaching effect. Besides, the thesis also explores its application for English teaching and strategies of introducing euphemism to students based on the theoretical analysis. It is hoped that the study will help with the collaboration of the relationship between teachers and students, establish harmonious teaching atmosphere and achieve the win-win teaching aim for both teachers and students.

Due to the limitation in data and the energy of the author, the strategies proposed in this thesis and their effect in teaching practice surely still need to be further examined and measured. Therefore, the study made in this thesis is open to discussion. Considering the enormous significance of euphemism for English teaching and communication among people, the study on it as well as its application has the full reason to expect more attention from college English teachers. It is believed that with more experimental application and teaching practice, euphemism will serve better for the improvement of students' language competence and the quality of college English teaching, and furthermore contribute a lot to crosscultural understanding and communication.

\section{ACKNOWLEDGMENT}

It is none but Professor Guan Shuhong who deserves my heartfelt thanks and respect for her continued support, precious suggestions and painstaking modifications during the writing of this dissertation. I could not have done it without her.

There are many other people who contributed to this dissertation in many respects. First, I would like to thank Wang Ning, for being so easy to work with. I want to thank him especially for his patience and constructive advice to perfect my dissertation.

Second, I would like to extend thanks to my friend for teaching me some computer skills to revise my dissertation. I am also indebted to her for her unwavering encouragement.

Last but not least, I am extremely grateful to my parents for their emotional support and care over the years.

\section{REFERENCES}

[1] Adams, M. Another Effing Euphemism [J]. American Speech, 1999, 94 (1), 110-112.

[2] Allen, K. and Burridge. K. Euphemism and Dysphemisms: Language Used as Shield and Weapon [M]. Oxford: Oxford University Press, 1991.

[3] Brown, P. and Levinson, S. C. Politeness: some universals in usage [M], Cambridge:Cambridge University Press, 1987.

[4] Chunbao Liu, A Dictionary of English Euphemism[M]. Beijing: The Commercial Press.

[5] Goffman, E. Forms of Talk[M]. Philadelphia: University of Pennsylvania Press. 1981.

[6] Grice, H. P. Logic and conversation [A], in Cole, p. and Morgan, J. (Eds.) Syntax and Semantics 3: Pragmatics [C]. New York: Academic Press, 1975.

[7] Grice, P. Studies in the Ways of Words. Cambridge, MA: Harvard University Press, 1989.

[8] H.W. Fowler: A Dictionary of Modern English Usage[M]. Oxford University Press, London, 1995:171

[9] Leech, G. N. Principles of Pragmatics [M]. London: Longman, 1983.

[10] Rawson, H. A Dictionary of Euphemisms and Other Double-talk [M]. New York: Crown Publishers, 1981.

[11] Warren, B. What euphemisms tell us about the interpretation of words [J]. Study linguistics,1992(a): 72-128

[12] Widdowson, H. G.. Aspects of Language Teaching[M]. London: Oxford University Press, 1990.

[13] Zhaoxiong He, A New introduction to Pragmatics [M]. Shanghai: Shanghai Foreign Language Education Press. 